\title{
Nasolacrimal Duct Obstruction Review
}

\author{
Nava Castañeda Angel ${ }^{1}$ and Velasco Y Levy Adriana ${ }^{2 *}$ \\ ${ }^{1}$ lacrimal Surgeon, Ophthalmology Institute, Mexico \\ ${ }^{2}$ lacrimal system resident, Ophthalmology Institute, Mexico
}

Submission: February 14, 2017; Published: July 06, 2017

*Corresponding author: Velasco Y Levy Adriana, Ophthalmologist, orbit, oculoplastic and lacrimal system resident. "Conde de Valenciana I.A.P". Ophthalmology Institute, Chimampopoca 14, Col Obrera, Mexico, Tel: 5554421700; Email: dravelascoylevy@hotmail.com

\begin{abstract}
Anatomical obstruction refers to any structural pathology in the lacrimal outflow pathway which hinders tear drainage1. It can be congenital or acquired. It is mostly presented in infants under 2 years old and in adults over 50 . A detailed history of any systemic or topical medication, surgery, trauma or scarring, and infection must be obtained for determine the etiology and the possible nasolacrimal pathway blocking site. This is a short review about the congenital and acquired forms, how it is diagnosed and its main features.
\end{abstract}

Keywords: Congenital lacrimal obstruction; Acquired lacrimal obstruction; Acute dacryocistitis; Chronic dacryocistitis

\section{Introduction}

The lacrimal system comprises two components the main and accessory lacrimal glands and their secretions and the lacrimal excretory system [1]. The lacrimal excretory system is divided into the proximal and distal sections. The proximal section includes the punctum, canaliculus, and the common canaliculus [2,3]. The distal lacrimal drainage system consists of the lacrimal sac and the nasolacrimal duct that finally ends under the inferior turbinate and empties into the inferior meatus [2].

The precorneal tear film is composed of aqueous, mucinous and oily components and is necessary for the maintenance of the cornea as well as the maintenance of the ocular surface epithelium. More than $90 \%$ of the lacrimal fluid is removed by the excretory system, whereas less than $10 \%$ evaporates between blinks. Outflow is mainly regulated by the pumping effect of the orbicularis oculi muscle (Horner muscle) $[3,4]$. Tears are thus drawn into the lacrimal excretory system after each blink. The passage of tears down the nasolacrimal duct is influenced by gravity, evaporation in the nose, and inspiration and expiration.

\section{Diagnosis}

A detailed history of any systemic or topical medication, surgery, trauma or scarring, and infection must be obtained. It is valuable to grade the severity of epiphora using a uniform grading system such as the Munk scale [5]. Slit lamp examination starts with recognizing the papilla, presence of a membrane or fibrosis over the punctum, punctum size, tear meniscus height, eyelid margin, conjunctiva around the punctum, eyelid malposition, position of the punctum in the tear lake, and any sign of previous surgery. The Schirmer test [6], tear break up time [7], ocular surface staining, and tear meniscus height will rule out any associated ocular surface abnormalities. Abnormal dye disappearance test is a very maneuver to assess abnormal tear drainage system and is especially helpful in pediatric patients [7].

\section{Congenital Nasolacrimal Duct Obstruction}

Congenital nasolacrimal duct obstruction is the first cause of pediatric epiphora. Other causes include congenital punctum and canaliculus stenosis and/or atresia, nasal malformations and craneofacial abnormalities. It is frequently seen at birth due to lack of perforation of the valve of Hasner or an inferior and distal nasolacrimal duct opening failure. At birth, half of the nasolacrimal new born pathways are not permeable. A spontaneous apoptosis mechanism takes place between $3^{\text {rd }}$ $4^{\text {th }}$ weeks after birth. Nevertheless, the obstruction persists in approximately $20 \%$ of the patients. Symptoms of congenital nasolacrimal duct obstruction consist of epiphora and dacryocystitis. The diagnosis is easily made in the office by observing epiphora and mattering of the eyelashes (Figure 1). It can be confirmed by compression over the nasolacrimal sac, which results in regurgitation of mucopurulent material in those patients who have developed chronic dacryocystitis. Instillation of $2 \%$ fluorescein dye and observation of abnormally delayed passage from de cul-de-sac is helpful in confirming the diagnosis. 


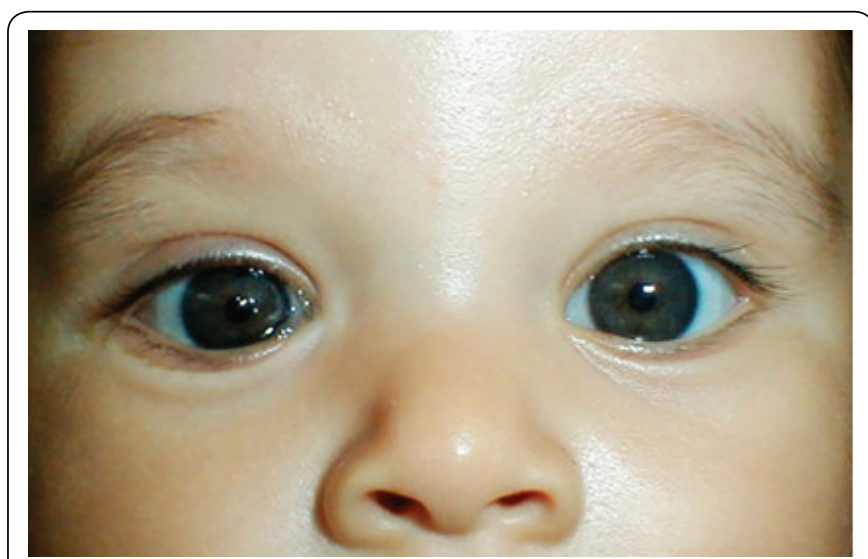

Figure 1: Congenital dacryoestenosis. Increase of the tear meniscus of the right eye.

\section{Dacryocele (Amniocele or Dacryocystocele)}

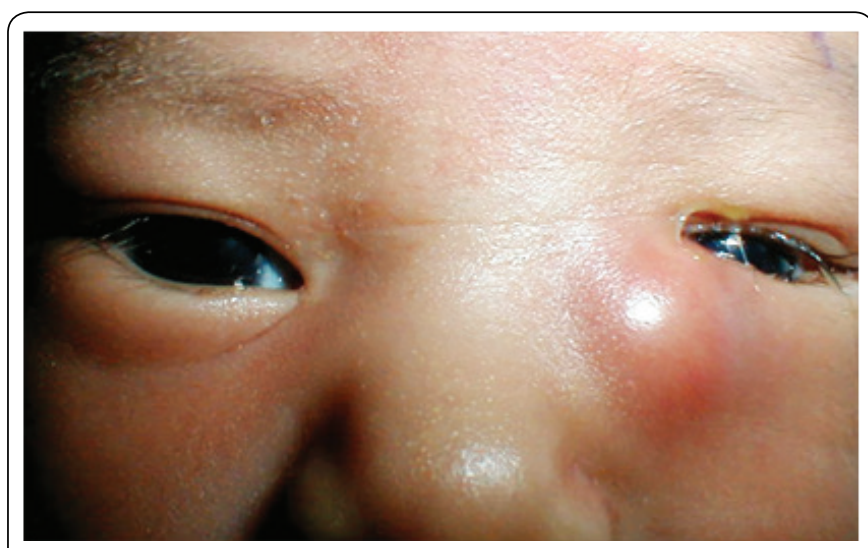

Figure 2: Left Dacryocystocele: Erythematous nodule in a newborn lacrimal sac area. Redness and swelling skin.

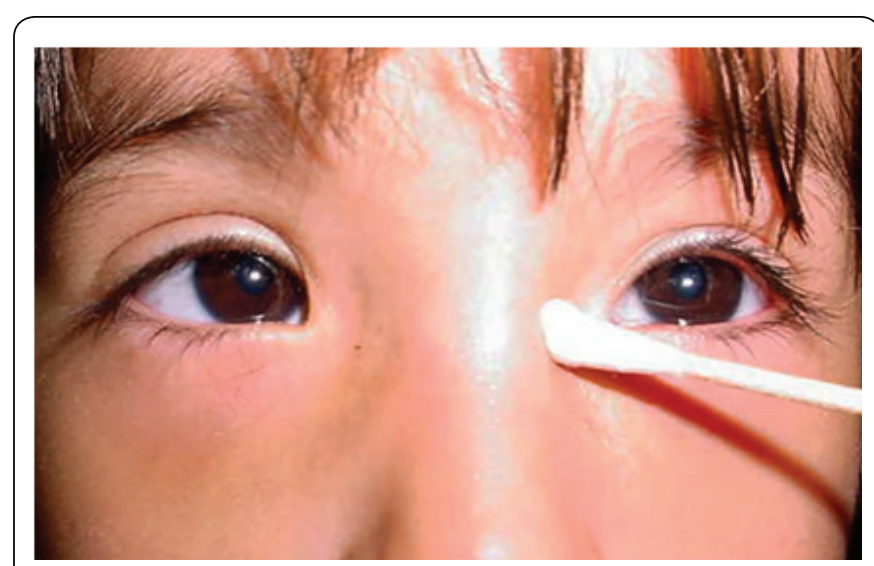

Figure 3: Local massage is performed by pushing down with a hyssop in the lacrimal pathway area in Hasner valve direction where the obstruction is located.

This is a rare entity presented at birth or within the fourth week after birth. The blockage is generally located at the nasolacrimal duct and at the Rosenmüller valve. An edematous, tender and red mass below the medial canthal tendon will be clinically found (Figure 2). Conservative management (medical treatment). If dacryocele is initially sterile, all patients must be treated with warm compresses, local massage and topical antibiotics [8]. Those infected will be treated with broad spectrum intravenous antibiotic therapy [9]. Local massage by pushing down the lacrimal sac is useful and accelerates the lumen duct perforation process (Figure 3). Controversy exists whether conservative management or early probing for decompression are preferable.

\section{Surgical Management of Congenital Nasolacrimal Obstruction}

Probing consist by introducing a thin metal probe into the lacrimal punctum trough the nasolacrimal pathway, producing a mechanical opening in the obstruction site. It is an operating room procedure under general anesthesia. The ideal time is controversial, most of the time the procedure is performed around the first year of life for those patients that did not show spontaneous improvement or despite conservative treatment [10].

Close dacryointubation is performed by placement of silicone stents through the superior and inferior canaliculus and down to the nasolacrimal duct. This dilates the inferior meatus. The duration of the stent employment ranges from 6 weeks to 6 months [10]. Dacryocystorhinostomy surgical procedure involves the removal of bone adjacent to the lacrimal sac draining directly into the nasal cavity and it is performed when siliconte intubation have failed.

\section{Differential Diagnosis}

Dermoid cyst, dongenital glaucoma, acute conjunctivitis, corneal abrasion, trichiasis, ocular foreign body sensation and meningoencephalocele must be discarded.

\section{Acquired Nasolacrimal Duct Obstruction}

The primary acquired nasolacrimal duct obstruction is caused by inflammation or fibrosis without any precipitating cause. Appears in middle age and elderly females in 3:1 ratio. The obstruction site is located in the lower nasolacrimal fossa and middle nasolacrimal duct. The secondary acquired obstruction is caused by inflammation or fibrosis with precipitating causes as infectious, inflammatory, neoplastic, traumatic or mechanical factors $[11,12]$.

Clinical presentation Patients with primary acquired nasolacrimal duct obstruction most commonly present with a history of epiphora. A chronic dacryocystitis owing to tear stasis can show a mucopurulent discharge at the punctum, or pus can be expressed from the punctum by massage of the lacrimal sac. Two stages can be distinguished [13].

\section{Acute Dacryocystitis}

Is an acute inflammation of the lacrimal sac due mostly to the obstruction of nasolacrimal duct. In most cases is a clinical diagnosis. Lacrimal sac bacterial overgrowth and inflammation 
occludes the superior and the natural drainage creating a true abscess. Symptoms and signs include a no compressible painful and erythematous mass below the medial canthal tendon. Medical treatment must be initiated because of the risk of extension to the periocular tissues and the orbit (Figure 4) including topical and systemic antibiotics, analgesics and antiinflammatory measures. Local heat and massages helps drainage and the opening of the obstruction site.

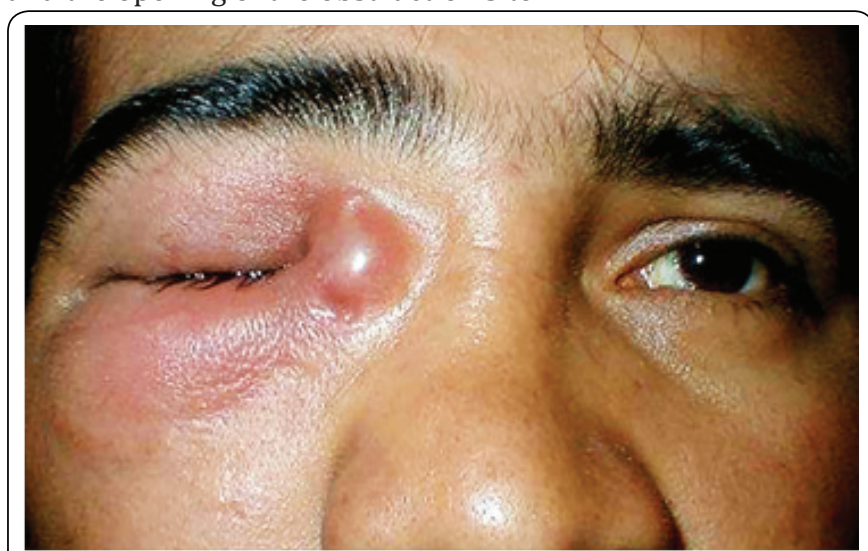

Figure 4: Acute dacryiocystitis. Swelling and tenderness at the right lacrimal sac level. Spread infection to the inferior eyelid producing a preseptal cellulitis.

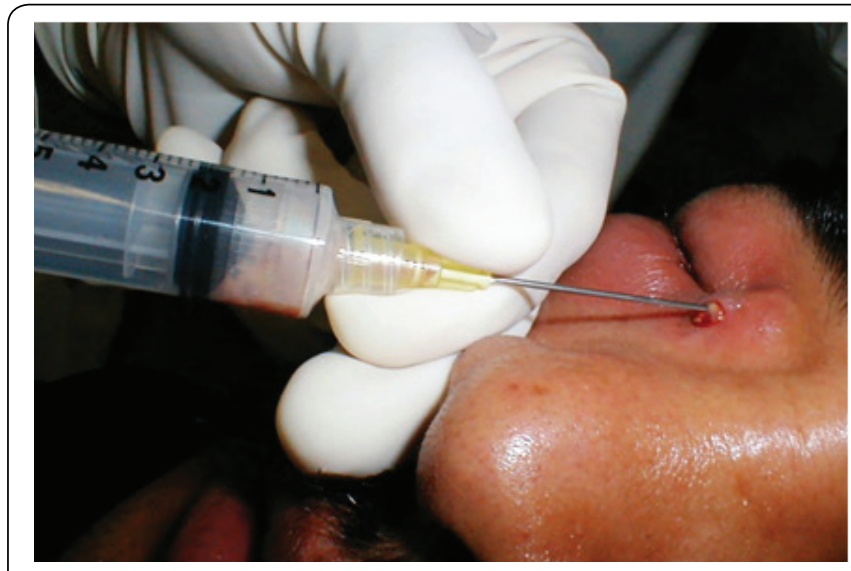

Figure 5: Lacrimal sac abscess. Percutaneous drainage, with hematic and purulent discharge that will be cultivated.

Lacrimal sac abscess requires sometimes manual percutaneous drainage, material can be collected and cultivated (Figure 5). Avoid irrigation during the acute phase because the risk of dissemination of the infectious process. Definitive treatment is a dacryocystorhinostomy procedure which can be performed as an external or internal endoscopic. It is preferable to postpone two or three weeks after the acute phase resolution.

\section{Chronic Dacryocystitis}

Symptoms and signs include recurrent epiphora, swelling and redness at medial canthus and a painless and compressible mass below the medial canthal tendon. The patient usually refers history of previous acute dacryocistitis or chronic unilateral conjunctivitis.
The lacrimal sac is filled with mucoid or purulent discharge that can be expressed frequently with local massage (Figure 6). Medical treatment includes topic and systemic antibiotics and a dacryocystorhinostomy as the surgical first choice. Differential Diagnosis: Preseptal cellulitis, sinusitis, canaliculitis, sebaceous cyst and neoplastic tumours.

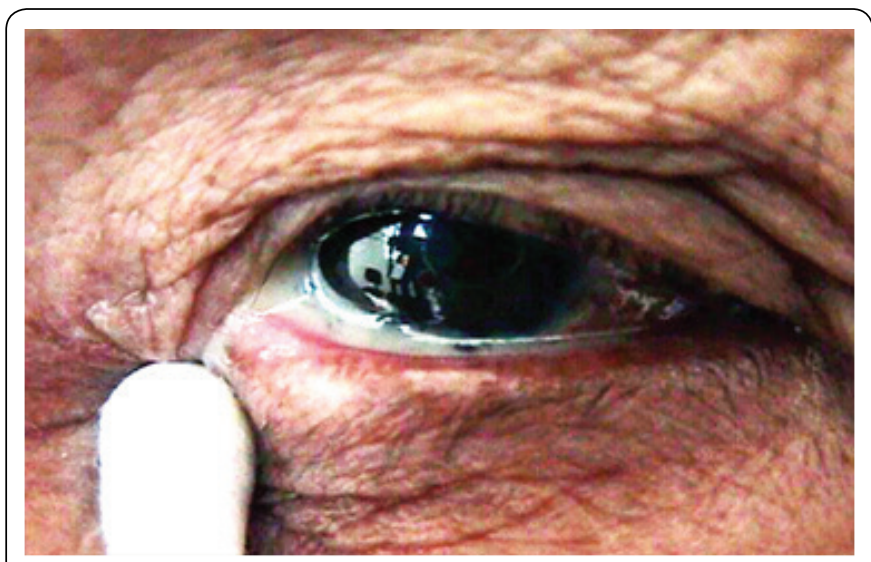

Figure 6: Chronic dacryocystitis. By the manual expression a mucopurulent discharge trough the lacrimal punctum was obtained.

\section{Conclusion}

For most tearing patients a diagnosis can be arrived at after a thorough history and a few relatively simple office procedures. A small number of cases will require more sophisticated studies to confirm the site of anatomic block. With the various test available, appropriate medical or surgical management can be determined in the vast majority of patient with tear production and drainage imbalance. Nasolacrimal duct obstruction is a common finding and the ophthalmologist must be prepared to recognize signs and symptoms to perform an accurate diagnosis and offer a correct management.

\section{References}

1. Hurwitz JJ (1996) The lacrimal system. Lippincott-Raven Publishers, Philadelphia, USA.

2. (2008-2009) Basic and Clinical course. Section 7, Orbit, Eyelids and Lacrimal System. American Academy of Opthalmology 259-64.

3. Meyer-Rüsenberg HW, Emmerich K (2010) Modern Lacrimal Duct Surgery From the Ophthalmological Perspective. Dtsch Arztebl Int 107(14): 254-258.

4. Tucker NA, Tucker SM, Linberg JV (1996) The anatomy of the common canaliculus. Arch Ophthalmol 114(10): 1231-1234.

5. Paulsen F (2008) Anatomie und Physiologie der ableitenden Tränenwege. Ophthalmologe 105: 339-345.

6. Munk PL, Lin DT, Morris DC (1990) Epiphora: Treatment by means of dacryocystoplasty with balloon dilation of the nasolacrimal drainage apparatus. Radiology 177(3): 687-690.

7. Kashkouli MB, Pakdel F, Amani A, Asefi M, Aghai GH, et al. (2010) A modified Schirmer test in dry eye and normal subjects: Open versus closed eye and 1-minute versus 5-minute tests. Cornea 29(4): 384-387.

8. Kushner BJ (1982) Congenital nasolacrimal system obstruction. Ophthalmology 100(4): 597-600. 
9. Grin TR, Mertz JS, Stass-Isern M (1991) Congenital nasolacrimal duct cysts in dacryocystocele. Ophthalmology 98(8): 1238-1242.

10. Katowitz JA, Welsh (1987) Timing of initial probing and irrigation in congenital nasolacrimal duct obstruction. Ophthalmology 94(6): 698705 .

11. Monka Anila, Zhugli Sulejman (2016) Nasolacrimal Duct Obstruction in adults. International Journal of Science and Reseach (IJSR) 5(1): $1327-1329$.
12. Linberg JV, McCormick SA (1986) Primary acquired nasolacrimal duct obstruction: a clinicopathologic report and biopsy technique. Ophthalmology 93(8): 1055-1062.

13. Bartley GB (1992) Acquired lacrimal drainage obstruction: an aetiologic classification system, case reports, and a review of the literature. Ophthalmic Plastic Reconstr Surg 8(4): 237-242.

This work is licensed under Creative Commons Attribution 4.0 License

DOI: $10.19080 / J 0 J 0.2017 .03 .555619$

\section{Your next submission with Juniper Publishers} will reach you the below assets

- Quality Editorial service

- Swift Peer Review

- Reprints availability

- E-prints Service

- Manuscript Podcast for convenient understanding

- Global attainment for your research

- Manuscript accessibility in different formats

( Pdf, E-pub, Full Text, Audio)

- Unceasing customer service

Track the below URL for one-step submission https://juniperpublishers.com/online-submission.php 